\title{
GAMES E EDUCAÇÃO: CONSIDERAÇÕES SOBRE ASSASSIN’S CREED E O ENSINO DE HISTÓRIA
}

\author{
Elvis Leonardo Sena Severo ${ }^{1}$, Jeong Cir Deborah Zaduski ${ }^{2}$ \\ ${ }^{1}$ Graduado em História com especialização em Língua Portuguesa, Gestão Pública e Design Instrucional para EaD. \\ Especializando em Mídias na Educação pela Universidade Federal de Juiz de Fora - UFJF. Docente de História do \\ Colégio Militar de Juiz de Fora - CMJF. \\ ${ }^{2}$ Doutoranda em Educação pela Universidade Estadual Paulista - UNESP. E-mail: deborah zaduski@hotmail.com
}

\begin{abstract}
RESUMO
Diante da constatação das mudanças significativas que são introduzidas na sociedade contemporânea por meio dos avanços tecnológicos e, dentro deste contexto, a ocorrência de novas relações no processo e ensino e aprendizagem, o objetivo deste texto foi refletir sobre as possibilidades que o game de temática histórica Assassin's Creed tem oferecido para a prática docente em sala de aula. $O$ estudo de caráter qualitativo foi pautado em uma revisão bibliográfica na qual foram investigadas questões como: o surgimento e as características do nativo digital e, em que medida suas experiências com a tecnologia estão sendo consideradas no planejamento do ensino; a pertinência da utilização dos games no ambiente escolar e o abismo que a escola tradicional mostra ao não valorizar um recurso que faz parte do cotidiano de seu novo aluno, recurso que possui um ótimo potencial para o desenvolvimento cognitivo ao se considerar o ambiente de performance em que ficam submetidos os gamers/alunos durante sua prática. Por fim o texto busca mostrar as potencialidades da franquia Assassin's Creed para o fazer pedagógico ao discorrer sobre um projeto de ensino desenvolvido em contexto educacional brasileiro e que obteve sucesso ao utilizar este jogo como recurso didático.
\end{abstract}

Palavras-chave: Games. Assassin's Creed. Ensino de História

\section{GAMES AND EDUCATION: CONSIDERATIONS ABOUT ASSASSIN'S CREED AND HISTORY TEACHING}

\begin{abstract}
Facing the confirmation of the significant changes that are insert in the contemporary society through technological advances and within this context, the occurrence of new interactions of the educational and learning process, the goal of this paper is to consider the possibilities that the game Assassin's Creed has offered to the teaching practice inside the classroom. The qualitative study was based on a bibliographical review in which questions were investigated as: The emergence and the digital native characteristics and how frequent its experiences with technology are been considered in teaching planning. The relevance of games use inside the educational environment and the abyss presented by the traditional school to not value a resource that is part of its new student's routine, a resource that has great potential to cognitive development when considering the performance environment that gamers/students are put into during its practice. Finally the text aims to show the potentialities that Assassin's Creed franchise has to pedagogy when discoursing about a new teaching project developed in a Brazilian educational context which obtained success while using this game as a didactic resource.
\end{abstract}

Keywords: Games. Assassin's Creed. History Teaching.

\author{
INTRODUÇÃO \\ Diante dos avanços tecnológicos \\ testemunhados pela sociedade contemporânea \\ percebe-se uma alteração nas relações sociais. 0 \\ ambiente escolar também sente os impactos \\ destas modificações. No entanto, em muitos
}

casos a escola não acompanha esta nova realidade. Este ambiente está agora mobiliado por um novo aluno, o nativo digital (MATTAR, 2014).

Deixar de conhecer as características e demandas deste novo aluno pode ser um sério 
obstáculo para a eficiência no processo de ensino e aprendizagem. Isto porque este aluno tem novas aspirações, novos gostos, como por exemplo a internet e os jogos, sejam eles através de aplicativos (também conhecidos como APPs), consoles ou computador (PC). Mas afinal quem é este novo aluno e, quais suas características?

Dentro deste contexto, há a necessidade de se adotar novas estratégias didáticas que pensem em recursos diferenciados dos tradicionais. Há exemplos de professores que utilizam o game com razoável sucesso em suas aulas ${ }^{1}$, por ser um recurso familiar ao aluno e captar sua atenção.

De acordo com Alves e Coutinho (2016), a discussão sobre a utilização dos games como recurso didático tem avançado bastante nos últimos anos. Por sua vez, Silva (2014) percebe o game Assassin's Creed como um excelente potencial para a utilização em contexto educacional, seja pela preferência dos jovens, seja pela temática histórica que ele aborda.

$\mathrm{Na}$ disciplina de História, há muitas possibilidades do uso desse game e também já é perceptível uma literatura que trata dessas questões, seja no âmbito da prática, seja em termos conceituais. Nesta perspectiva, busca-se investigar: Em que medida o uso do game Assassin's Creed tem contribuído no ambiente escolar, em especial nas aulas de História?

\section{METODOLOGIA}

O tipo de pesquisa aplicada, quanto à abordagem do problema, classifica-se como qualitativa, já que a interpretação dos fenômenos e a atribuição de significados são básicas nesse tipo de processo. Neste tipo de pesquisa, a abordagem é realizada com o objetivo de "[...] aprofundar-se na compreensão dos fenômenos que estuda [...] interpretando-os segundo a perspectiva dos próprios sujeitos que participam da situação, sem se preocupar com representatividade numérica. [...]" (GUERRA, 2014, p. 11). Assim, as ações dos sujeitos são consideradas no seu contexto social, o que foi justamente buscado na proposta deste trabalho ao investigar os aspectos pertinentes da prática

\footnotetext{
${ }^{1}$ Entre os exemplos, é possível destacar a atuação de Marilli Bassini, professora do Colégio Objetivo de Americana que organizou um estudo de períodos históricos retratados em jogos eletrônicos famosos entre os alunos. A proposta foi muito bem aceita pelos alunos. Disponível em: <http://porvir.org/professora-desenvolveprojeto-usa-games-para-estudar-historia/>. Acesso em 20 jul. 17.
}

docente e discente com jogos digitais no ambiente escolar.

A fundamentação teórica baseou-se em pesquisa bibliográfica, explorando a literatura nas temáticas: Tecnologias da Informação e da Comunicação (TICS), educação no contexto do século XXI, o novo perfil do aluno contemporâneo e as possibilidades do uso do game na educação. Além do respaldo teórico encontrado em capítulos de livros e artigos científicos, foram consultados vídeos, artigos e entrevistas disponíveis eletronicamente, a fim de alcançar as discussões da produção acadêmica atual sobre o tema em estudo.

Não menos importante foi a consulta em periódicos especializados em jogos digitais (revista EGW), fundamentais para compreender os aspectos técnicos deste recurso tecnológico e, uma entrevista, indispensável para perceber a real potencialidade (prática) do jogo no contexto educacional.

\section{O tempo contemporâneo e o surgimento do nativo digital}

Uma tentativa de compreender essa nova geração que possui um perfil marcado pela influência da tecnologia pode ser viável através do conceito de nativo digital, que segundo as pesquisas de Carniello, Rodrigues e Moraes $(2010$, p. 2) seriam "[...] jovens que falam com naturalidade e sem sotaque, o idioma digital destes recursos eletrônicos, como se essa fosse a língua deles." Eles se adaptam facilmente às rápidas mudanças da sociedade, estão frequentemente conectados e são apaixonados por games.

João Mattar, uma referência nacional no que se refere ao uso de games na educação, se apoia em Marc Prensky (2001) para apontar algumas diferenças básicas entre o nativo e o imigrante digital, diante desta perspectiva,

Os nativos digitais seriam
aqueles que nasceram e
cresceram na era da
tecnologia digital,
enquanto os imigrantes
digitais, por sua vez,
nasceram na era
analógica, tendo migrado
posteriormente para o
mundo digital. Por
consequência, os nativos e
os imigrantes digitais
pensariam e processariam
informações de maneiras


distintas, o que deveria ser levado em consideração no design de atividades de ensino e aprendizagem. (MATTAR, 2014, p.35)
O quadro a seguir, elaborado por Mattar, apresenta algumas distinções entre o nativo e o imigrante digital que são bastante significativas para pensar como cada categoria interage no meio social.

Quadro 01. Imigrante x Nativos Digitais

\begin{tabular}{|l|l|}
\hline Imigrantes Digitais & Nativos Digitais \\
\hline Livros & TV, internet e games \\
\hline Textual & Visual \\
\hline Método & Tentativa e erro \\
\hline Ordem & Acesso randômico \\
\hline Uma coisa por vez & Multitarefas \\
\hline Aprendizado individual & Aprendizado colaborativo \\
\hline
\end{tabular}

Fonte: elaborado por Mattar (2014, p. 35)

A partir das informações constantes do quadro acima, é possível presumir que uma boa parte dos professores atuais possuem características similares às dos imigrantes digitais, no entanto isso não pode ser considerado como obstáculo para as relações necessárias no processo de ensino e aprendizagem. É importante conhecer este ambiente de imersão proporcionado pelo mundo tecnológico, e assim buscar o aperfeiçoamento constante e pensar não mais como um profissional que irá ensinar, e sim, mediar relações para a produção do conhecimento, utilizando-se para isso dos recursos disponíveis e sempre levando em consideração as demandas dos alunos. Nesse sentido, com base nos textos lidos e nos relatos de experiências encontrados, é possível inferir que o game tem sido uma dessas demandas.

Diante da constatação desta realidade, um questionamento relevante é pensar qual é a forma que os nativos digitais se relacionam com os jogos eletrônicos e como esse potencial pode ser apropriado para o ambiente educacional.

\section{Relação entre games e ambiente escolar}

Segundo Arruda (2011), atualmente muitos jovens passam mais tempo em frente a um jogo de computador ou console de vídeo game que propriamente no ambiente escolar. Esta experiência se inscreve assim como lugar de destaque para crianças e adolescentes. Isso mostra que a escola, de certa forma, perdeu sua centralidade nos processos formativos das gerações mais novas. O autor complementa que esta realidade se apresenta, com maior frequência, nos meios urbanos desenvolvidos.

Por sua vez Bannel et al, percebem um deslocamento entre a realidade e a sala de aula, tornando assim a escola um lugar de ausência. Os autores criticam esta falta de ancoragem da produção do conhecimento à realidade cotidiana dos alunos e afirmam que esta situação limita a aprendizagem a um processo de repetição. No entanto, os autores acreditam que

[...] a sala de aula tenha
potencialidade de se
tornar um lugar de
presença, a partir da
conexão com algumas
experiências que os corpos
já conhecem, para sua
sucessiva abstração lógica.
Do mesmo modo como,
hoje, as tecnologias
digitais representam
lugares de simulação, de
presença e de
aprendizagem para as
novas gerações. (BANNEL
et al, 2016, p. 115)

Nos deparamos com um cenário educacional no qual cada vez mais as instituições sofrem com o desinteresse dos alunos, o que pode ser uma das causas para a evasão e o baixo rendimento. Deste modo, é necessário repensar alternativas que possam resgatar a motivação dos alunos e assim, possibilitar uma aprendizagem significativa. A utilização de jogos interativos pode proporcionar um ganho 
significativo no processo de ensino e aprendizagem. Neste contexto, "[...] os jogos oferecem a oportunidade de ampliar o potencial do uso de imagens, animações e interatividade, além de resgatar o aspecto lúdico e prazeroso da aprendizagem." (MILITÃO; FREITAS; SALVADOR, 2015, p. 85).

Ratificando essa posição que defende o uso dos games como recurso didático, Arruda (2011, p. 15) observa que "[...] jovens com acesso a diferentes mídias digitais criam novas relações com os saberes, novas maneiras de interpretar o mundo e, novas formas de aprendizagem e de construção do saber [...]". Os jogos digitais atuais, por suas características, exigem dos jogadores níveis de elaboração mentais diferenciados e bastante complexos.

Partindo da teoria à prática, é possível observar experiências que se inserem neste contexto, ou seja, práticas pedagógicas que lançam mão de estratégias que têm o game como recurso didático. Rodrigues et al (2016) apresentam dois projetos instaurados em uma escola pública do Rio de Janeiro. Os autores iniciam a apresentação dos projetos afirmando que "[...] com o advento dos jogos digitais na educação, como dinamizadores do ensino, surge a possibilidade destes serem utilizados como recurso didático no processo de ensino e aprendizagem." (RODRIGUES et al, 2016, p. 1)

Os projetos pedagógicos foram implantados nos sextos e sétimos anos no Ensino Fundamental. Os professores idealizadores utilizaram alguns softwares e os alunos produziram de forma colaborativa dois jogos de cartas, um deles na disciplina de Geografia que teve como temática as paisagens naturais e, outro na disciplina de Ciências tendo como tema a evolução das espécies, que possui uma dinâmica semelhante ao jogo 'Pokemon $\mathrm{Go}^{2}$. Logo percebe-se a atenção ao aspecto lúdico e prazeroso da prática que é familiar aos jovens com faixa etária destes anos escolares.

Entre os aspectos observados, percebeuse que a inserção dos games como atividade pedagógica proporcionou certos benefícios, entre o quais:

$\begin{array}{lr}\text { [...] facilitador } & \text { e } \\ \text { dinamizador } & \text { do } \\ \text { aprendizado, } & \text { efeito } \\ \text { motivador, } & \\ \text { desenvolvimento } & \text { de }\end{array}$

${ }^{2}$ Pokémon GO é um jogo eletrônico livre de realidade aumentada voltado para smartphones. habilidades cognitivas,

aprendizado por descoberta, experiência de novas identidades, socialização, coordenação motora e comportamento expert. Além de proporcionar aos alunos a possibilidade de serem sujeitos num processo de aprendizagem em conjunto com colegas e professores em um ambiente de colaboração. (RODRIGUES et al, 2016, p. 2).

Entre os resultados alcançados pelos alunos pode-se perceber, o aprendizado dos conteúdos abordados, a capacidade de utilização das ferramentas computacionais sugeridas e necessárias para o desenvolvimento das tarefas, ou seja, os alunos, interagiram entre si e utilizaram conjuntamente a tecnologia para a produção do conhecimento, utilizando uma metodologia que se caracterizou, entre outros aspectos pela capacidade de busca, seleção e tratamento da informação. Também foi observado o desenvolvimento de aspectos sócio afetivos como a capacidade de trabalhar em grupo, responsabilidade e colaboração. Estes aspectos são fundamentais para a produção coletiva do conhecimento.

Diante dos positivos resultados obtidos em práticas que utilizam os games como recurso pedagógico na educação, como os apresentados nesta escola pública do Rio de Janeiro, que aspectos são possíveis observar durante a prática efetiva do game, ou seja, durante a imersão do estudante no jogo digital?

\section{Games: o ambiente de performance e a aprendizagem}

João Mattar (2014) menciona que os games prendem a atenção dos jogadores e geram aprendizado. Um gamer (jogador) se encontra normalmente em "[...] um estado de concentração ou completa absorção com a atividade ou situação em que está envolvido, motivação e imersão total no que está fazendo, atenção focada e harmonia." (MATTAR, 2014, p. 43) $O$ autor destaca o fato do game prender a atenção dos jovens em situações não muito fáceis, nem muito difíceis pois em ambos os casos poderia haver desinteresse, seja pela ausência de 
situações desafiadoras, seja pelo fracasso constante. Ou seja, esse é exatamente o mecanismo necessário para a aprendizagem, segundo Vygotsky (1987), que afirma que a aprendizagem ocorre quando o aprendiz é estimulado na medida certa ${ }^{3}$.

Baseando-se nestas considerações, Mattar afirma que esta deve ser uma preocupação constante do design instrucional, mesmo porque os princípios do design de games estão associados ao aprendizado, logo, podem ser utilizados na educação. Neste contexto, são várias as estratégias existentes nos games que o tornam atrativo aos jogadores. Atualmente eles conseguem adaptar cada momento de uma experiência às habilidades dos jogadores. Podem também,

[...] determinar o 'estilo de conforto' de aprendizagem do jogador, e, a partir daí, em vez de se adaptar a esse estilo de aprendizagem, realizar 0 oposto: se o jogador prefere ter muita informação antes de tomar uma decisão, o game fornece apenas um pouco; se 0 jogador prefere consultar outras pessoas, o game torna isso difícil [...]. Essa ideia de exercitar e forçar o aprendiz, em vez de apenas deixá-lo mais confortável, é típica das técnicas de aprendizagem inovadores embutidas nos modernos games eletrônicos que nossas crianças jogam. (MATTAR, 2014, p. 45).

Nesta perspectiva, é necessário pensar em estratégias que possam desenvolver nos alunos, através de suas características e habilidades potenciais, um aprendizado significativo e dentro das perspectivas dos objetivos pedagógicos necessários para o cumprimento da base curricular obrigatória do ensino escolar. Este é o grande desafio.

\footnotetext{
${ }^{3}$ A teoria de Vygotsky é baseada em um aprendizado que se processa na chamada Zona de Desenvolvimento Proximal que seria a distância entre o nível de desenvolvimento atual do aprendiz com o seu nível de desenvolvimento potencial.
}

Mattar (2014), ao analisar o ambiente da performance educacional percebe que há uma distinção entre o contexto da aprendizagem (onde a aprendizagem ocorrerá) e o contexto da performance (onde serão aplicadas as novas habilidades).

O ambiente de aprendizagem é caracterizado por vários fatores. Há a dimensão humana, na qual ocorrem as experiências entre aprendizes, professores e tutores. Existe a dimensão pedagógica, que engloba os diversos recursos e materiais pedagógicos. Há a questão do espaço físico e dos recursos tecnológicos, além de outros como cultura, valores objetivos institucionais mais amplos.

Ao considerar todos estes aspectos, e apoiado na Teoria da Cognição Situada e na Teoria da Aprendizagem Autêntica, Mattar tece as seguintes considerações:

A teoria da cognição
situada foca justamente
na transferência do
contexto da aprendizagem
para o contexto da
performance, e a teoria da
aprendizagem autêntica
enfatiza que os contextos
de aprendizagens devem
ser os mais autênticos
possíveis para apoiar a
transferência de
conhecimento da
educação formal para a
prática [...] (2014, p. 55).

Analisando o contexto educacional brasileiro, o autor percebe que, de acordo com estas teorias, há uma diferença entre o que é ensinado nas escolas e os usos e práticas cotidianas. Portanto, é essencial que seja realizada uma avaliação do ambiente de performance dos aprendizes, principalmente levando em consideração suas características de nativos digitais, para os quais entre as suas diversas práticas cotidianas, o game está presente com grande destaque.

Uma outra questão bastante pertinente é a forma de se lidar com o fracasso. Na educação tradicional, o erro é considerado um sinônimo de fracasso escolar, como uma forma punitiva. Por sua vez, o papel do erro no game é bem diferente:

Nos games, o custo do fracasso é normalmente diminuído - quando os 
jogadores fracassam, eles podem por exemplo recomeçar do último jogo salvo. Além disso, o fracasso, por exemplo, para matar um mestre, é em geral encarado como uma maneira de aprender e, na próxima oportunidade, tentar vencer. Essas características do fracasso nos games permitem que os jogadores arrisquem-se e experimentem hipóteses que seriam muito difíceis de testar em situações que o custo do fracasso fosse maior, ou onde nenhum aprendizado derivasse do fracasso. (MATTAR, 2014, p. 48)

No momento em que os fracassos se transformam em situações motivadores para o desenvolvimento de novas estratégias e habilidades na busca pelo êxito, o game pode ser visto como um recurso bastante positivo para ser planejado em ambiente educacional.

No entanto, mesmo que pesquisas apontem que "[...] jogar videogames leva à melhora na capacidade perceptiva e na atividade de processamento cognitivo, provoca reações mais rápidas [...] melhora a capacidade motora e acuidade visual [...]" (PETRY, 2016, p. 45) entre outras vantagens necessárias para o processo e aprendizagem, a transferência de aprendizagem proporcionada por jogos ocorre "[...] somente quando processos cognitivos semelhantes são encontrados nos jogos e nas tarefas externas" (PETRY, 2016, p. 46). Isso vem apenas reforçar a importância de se pensar o ambiente da performance no contexto escolar.

\section{O game e a História}

A temática em História vem ganhando um espaço significativo na produção de jogos digitais. Por outro lado,

[...] os jovens com acesso a diferentes mídias digitais criam novas relações com os saberes, novas maneiras de interpretar o mundo e, novas formas de aprendizagem e de construção do saber histórico [...] as mídias eletrônicas e digitais apresentam-se como um avanço tecnológico capaz de modificar nosso comportamento, com um discurso que se materializa em novas condições de possibilidades, novos espaços e assumindo novas formas. (ARRUDA, 2011, p.15)

É diante deste contexto, que os jogos atuais possuem uma linguagem que permite a representação da realidade com bastante riqueza de detalhes além de exigirem dos jogadores novas formas de elaboração mental. Mas em que medida o jogo ocupa o ambiente escolar no processo de ensino e aprendizagem? Em se tratando da disciplina História, os jogos digitais que são desenhados com o objetivo de possibilitar ao jogador a interação com diferentes formas de representação do passado ${ }^{4}$, têm sido adequadamente utilizados como recurso pedagógico nos bancos escolares brasileiros? Este é o questionamento do texto de Alves e Telles (2016). Segundo os autores, embora

[...] nas últimas décadas,
os debates e publicações
sobre o assunto tenham se
expandido, o uso da
aprendizagem baseada em
jogos eletrônicos na
educação formal ainda é
visto como algo de
natureza difícil e exótica
por muitos professores,
seja pelos problemas
envolvidos na observação
dos resultados ou pela
complexidade que envolve
os processos de avaliação
nessa área. Trata-se,
portanto de um campo de
inovação que ainda
encontra pouco espaço de
penetração nas escolas,
contrastando com o seu
crescimento nos debates

\footnotetext{
4 "São os jogos que utilizam na sua narrativa a História como via principal para o desenvolvimento do conflito do jogo, desde a elaboração dos cenários até os personagens. Assim, os temas históricos funcionam basicamente de duas maneiras, tanto como atrativos para o jogador instigar-se para começar e continuar no jogo, como ao contrário, o jogador começa a jogar e se interessa pela História. Isto vai depender da subjetividade e experiências do jogador." (SILVA, 2014, p. 41)
} 
acadêmicos. (ALVES; TELLES, 2016, p. 128)

Refletir sobre as possibilidades da utilização do game para a educação escolarizada pode ser um bom começo para possíveis planejamentos didáticos. Neste sentido, Alves e Telles (2016) expõem suas percepções sobre as potencialidades dos jogos digitais no processo de aprendizagem. Os autores visualizam três formas de aprendizagem através de games. A primeira delas é a aprendizagem através de jogos de computador que são desenvolvidos para o trabalho com conteúdos educacionais específicos.

Outra possibilidade é a que os autores chamaram de aprender com jogos, que se trata da adaptação de jogos que não possuem objetivos educativos e utilizados para este fim. A última forma mencionada é a denominada aprender fazendo jogos, que se trata do desenvolvimento de jogos através de projetos que viabilizem permitir "[...] a sistematização do conhecimento sobre determinado tópico. $\mathrm{O}$ jogo a ser desenvolvido pode ou não ter uma finalidade educativa." (ALVES; TELLES, 2016, p. 128) $O$ importante nesta forma de utilização dos games seriam as habilidades, competências e conhecimentos adquiridos durante $\mathrm{O}$ desenvolvimento do projeto.

Qualquer que seja a opção escolhida para se planejar um trabalho que envolva o game como recurso para a aprendizagem em História, isso dependerá dos recursos disponíveis, da qualificação do docente e não menos importante, da demanda dos alunos. Além disso, é necessário compreender que,

as dimensões temporais

do jogo introduzem o

jogador no percurso da construção de raciocínios e ideias históricas, necessários à aprendizagem da História. A dimensão temporal, seja ela a cronologia, a linearidade ou a simultaneidade dos acontecimentos, é um dos elementos mais complexos da compreensão da História. (ARRUDA, 2011, p. 51)
O autor menciona alguns exemplos de jogos com temática histórica que possuem uma dinâmica que pode ser observada por meio desse raciocínio histórico. Entre elas está o game Making History. Nele, os jogadores podem assumir o papel dos líderes dos principais países que estiveram envolvidos na Segunda Guerra Mundial. Partindo deste princípio, cabe ao jogador "[...] definir estratégias econômicas, bélicas e políticas para garantir a sua sobrevivência no ambiente hostil da época. As estratégias tomadas pelo jogador possuem estreita relação com os acontecimentos da época." (ARRUDA, 2011, p. 51)

A prática de Making History não apenas viabiliza a aquisição de conhecimento histórico factual presente no contexto do jogo, mas propicia o desenvolvimento de outras habilidades e competências como a percepção da História aberta às incertezas, ou a História sendo produto da interpretação dos documentos, ou até mesmo a História como invenção.

Arruda (2011) percebe estas possibilidades ao analisar que o jogo oferece outras opções aos jogadores, decisões de estratégias as quais levariam as nações a diferentes destinos dos atuais. Exemplos delas seriam a criação de uma aliança entre Estados Unidos e Alemanha, ou Japão e Inglaterra, alterando assim "[...] a história conhecida pelos jovens e tornando-os estrategistas de uma história construída pela sua mente criativa. [...]" (p. 51-52).

É justamente partindo desta perspectiva que o autor discute a relevância da relação entre imaginação e a construção da História nos jogos digitais. Segundo ele:

Verifica-se que o jogo
pressupõe doses de
imaginação, ainda que
apresente espaços
reduzidos para ação do
jogador. A imaginação
permite, ainda que,
potencialidades de
construção de narrativas
complementares ao jogo
[...] quando uma pessoa
pensa historicamente, tem
diante de si certos
documentos ou vestígios
do passado. A missão é
descobrir o que foi esse
passado, que deixou atrás
de si esses vestígios. Se,


por exemplo, os vestígios forem certas palavras escritas, é preciso descobrir o que é que tais palavras significam [...] isso implica desvendar o pensamento (no mais amplo sentido dessa palavra) expresso por meio delas. Para revelar o que esse pensamento era, o historiador tem de pensá-lo por si. Neste caso, o historiador necessita colocar-se no lugar do outro para compreender os aspectos históricos de determinada situação e utilizar sua capacidade imaginativa para preencher as lacunas deixadas pelas fontes. (ARRUDA, 2011, p. 163)

Muita similaridade ao que foi expresso acima pelo autor é encontrado no game Assassin's Creed, um jogo de temática histórica que será apresentado a seguir, em conjunto com os demais jogos desta franquia, demonstrando a potencialidade do seu uso como recurso didático para as aulas de História.

\section{Assassin's Creed}

"Essa Londres de 1868 está cheia da vida e os trens são uma parte importante desse mundo. O jogador vai poder não apenas viajar de trem, mas também andar no teto dele, do lado de fora e até roubar cargas."

Scott Philips

Este é o nível de imersão no ambiente histórico do game Assassin's Creed Syndicate, um dos jogos da franquia Assassin's Creed. Ambientado no cenário político da Era Vitoriana, o jogo traz uma Londres em plena Revolução Industrial e nele será possível dialogar com personagens como Charles Dickens, Charles Darwin e Jack o Estripador.

Em um jogo com ambiente histórico riquíssimo e intensa realidade virtual é importante pensar o que é Assassin's Creed e que potenciais o game oferece para o ensino de História. Traduzido para o português, Credo dos Assassinos, o jogo do gênero RPG e ficção histórica tem como principais características a ação e a aventura e, teve sua primeira versão produzida em 2007 pela empresa francesa Ubisoft localizada em Montreal e Quebec no Canadá.

O jogo que é disponível em várias plataformas como Playstation, Xbox, Nintendo Wii, entre outros, é centrado no conflito secular entre a Ordem dos Templários contra a Ordem dos Assassinos, desde a Idade Média até o tempo contemporâneo. Silva (2014) faz as seguintes considerações sobre o jogo:

Ele possui como um dos personagens principais Desmond Miles, que vive em 2012 e através das memórias de seus ancestrais retorna a momentos da Terceira Cruzada na Terra Santa (1191), do Renascimento Europeu, da Independência nos Estados Unidos e do contexto da pirataria na América Central do século XVIII, procurando impedir que os templários edifiquem uma nova ordem mundial. [...] O jogo também foi apropriado por outras linguagens como a literatura e o cinema. Transformou-se em livro, sendo todos publicados pela editora Penguin Books e escritos por Oliver Bowden. (SILVA, 2014, p. 45)

Além das continuações que são caracterizadas por enredos diferentes como mudanças de períodos históricos, o jogo possui várias expansões que são os jogos que continuam com o enredo semelhante, porém são acrescentadas outras versões do mesmo enredo, além da introdução de novos personagens.

0 primeiro lançamento da franquia foi em 2007 e o enredo gira em torno do personagem Desmond Miles, que vive no ano de 2012 e é inesperadamente sequestrado pela Indústria Abstergo (uma versão moderna da Ordem dos Templários), sendo forçado a reviver a memória de seus ancestrais com o objetivo de encontrar a Maçã do Éden, artefato de grande poder que é objeto de uma disputa secular entre as duas ordens. $\mathrm{O}$ ambiente do jogo é a época da Terceira Cruzada (1191), e o personagem/gamer 
percorrerá cidades como Damasco e Jerusalém, tendo como missão inicial o assassinato de nove templários.

Em 2009 é lançado Assassin's Creed II e o jogador pode comandar um outro ancestral de Desmond Miles, Ezio Auditore Da Firenze, que viveu no século XV. Assim é possível percorrer cidades renascentistas como Florença e Veneza. $\mathrm{O}$ assassino terá de ir ao Vaticano e vingar-se da morte do pai, assassinado pelo Papa Alexandre IV. A busca pela Maça do Éden também faz parte do enredo. O jogador poderá dialogar com importantes personagens históricos como Nicolau Maquiavel e Leonardo Da Vinci.

$\mathrm{Em}$ se tratando de conhecimento histórico, a imersão em Assassin's Creed II, pode trazer possibilidades significativas no campo do ensino e aprendizagem, isso porque:

$$
\begin{aligned}
& \text { Sua simulação reconstrói } \\
& \text { inúmeros elementos da } \\
& \text { cultura material do século } \\
& X V \text { e coloca o jogador no } \\
& \text { cenário das intrigas e dos } \\
& \text { conflitos políticos do } \\
& \text { período, além de } \\
& \text { disponibilizar um banco de } \\
& \text { dados com retratos, } \\
& \text { biografias e explicações } \\
& \text { sobre costumes e locais do } \\
& \text { Renascimento italiano. A } \\
& \text { sua narrativa ficcional é } \\
& \text { contextualizada } \\
& \text { historicamente, } \\
& \text { misturando personagens } \\
& \text { fictícios com personagens } \\
& \text { históricos. (ALVES; TELLES, } \\
& \text { 2016, p. 136) }
\end{aligned}
$$

Embora os autores estejam analisando o segundo lançamento da franquia, é possível estender seus comentários aos demais lançamentos. Uma das características da empresa Ubsofit é o pesado investimento em consultoria histórica e antropológica para a produção de cada jogo. Aliado ao fato de que os avanças em tecnologia trazem consoles com definição de imagem cada vez melhores, torna o contexto da realidade virtual mais intenso a cada lançamento.

No entanto, uma franquia que possui jogos com vários ambientes históricos retratados e com potencial imersivo significativo para o aprendizado, tem sido devidamente utilizada pelos professores de História no contexto educacional brasileiro?
Em reportagem publicada no site Porvir é possível encontrar um projeto desenvolvido por Marili Bassini ${ }^{5}$, professora de uma escola de Americana-SP que organizou um estudo sobre períodos históricos retratados em jogos eletrônicos praticados pelos alunos. Entre os jogos escolhidos, Assassin's Creed aparece com destaque.

A professora, que já participou de diversos programas de formação ao longo de sua carreira e também pelo fato de gostar de jogos, afirma que percebeu a existência de uma grande variedade de títulos disponíveis no mercado que poderiam ser explorados em sala de aula. $\mathrm{Na}$ entrevista a professora explica o que motivou esta iniciativa:

Sempre discuti a questão do que fazer de diferente na educação com o Fernando Arantes e a Miriam Oliveira, que são meus parceiros e coordenam o grupo de Projetos especiais para Inovação Educacional. A partir disso, resolvi tentar algumas experiências na disciplina de história com os meus alunos do ensino médio. Para criar um projeto, sempre tinha aquele pensamento de aproximar a prática da realidade deles. Observando o interesse dos alunos por jogos, eu comecei a perceber que eles tinham um fundamento histórico que poderia ser explorado em sala de aula de uma forma diferenciada, incentivando os estudantes pesquisarem sobre o período histórico tratado no jogo. (BASSINI, 2015, $\mathrm{s} / \mathrm{p})$

A proposta não se resumia ao conhecimento dos fatos e contextos históricos retratados nos jogos, mas também ao questionamento sobre a veracidade das informações pesquisadas. Neste projeto, a

\footnotetext{
${ }^{5}$ Marili Bassini é graduada em História com mestrado em História Cultural e Doutorado em Educação. É professora há mais de duas décadas, tendo experiência em todos os níveis de aprendizagem.
} 
docente assumiu o papel de mediadora no processo de produção do conhecimento na qual os alunos eram os protagonistas. A ação da professora estava bastante centrada na orientação aos alunos, seja na procura de sites para pesquisas, delimitação de temas, na indicação de fontes online confiáveis, entre outros.

Nesse sentido, Arruda (2011, p. 183) afirma que "[...] o contato com os jogos digitais de história permite ao jovem desenvolver estratégias de aprendizagem (em geral) e em História." Foi justamente esta a constatação da professora ao analisar o produto de seu projeto, ou seja, a apresentação em grupos dos trabalhos dos alunos para uma banca de professores. A maior parte dos grupos apresentou um trabalho excelente e foi perceptível a melhora significativa em vários aspectos, conforme relata a professora:

Só pelo fato do projeto envolver jogos, os alunos já têm um olhar diferente. Um deles veio me falar: 'Professora, eu espero há cinco anos para fazer um trabalho assim'. A leitura e interpretação de texto melhorou muito; a própria espacialidade melhorou, eles já conseguem montar na cabeça uma sequência histórica e entender que um fato está ligado ao outro. Além disso, eles passaram a olhar o jogo de forma diferente, questionando coisas que antes passavam despercebidas. (BASSINI, 2015, s/p)

O desenvolvimento destas habilidades muito se dá pelo fator de imersão no jogo Assassin's Creed. Por exemplo, em Assassin's Creed Unity que retrata a Revolução Francesa, o jogador pode interagir com personagens como Marquês de Sade, Thomas Paine, Luís XVI, Robespierre e o próprio Napoleão Bonaparte. Além da configuração do ambiente e contexto histórico, o que tais personagens oferecem sobre o passado torna-se bastante significativo para o sucesso da missão do assassino e por sua vez, para a compreensão da história pelo aluno.

\section{CONSIDERAÇÕES FINAIS}

A tecnologia no mundo contemporâneo é uma realidade e deve ser considerada no momento do planejamento educacional, uma vez que o contexto social e o contexto escolar devem estar lado a lado para um processo de ensino e aprendizagem mais eficiente.

o cenário educacional brasileiro apresenta muitas dificuldades. Entre as mais significativas está a diferença no modo de ver e agir no mundo entre os nativos digitais, que são na sua maioria os jovens alunos da atualidade e que possuem extrema facilidade no trato com os modernos recursos tecnológicos e, os imigrantes digitais, entre os quais, grande parte dos professores, que, por pertencerem a outra geração, em sua maioria não possuem as mesmas facilidades com o mundo digital. Essa diferença, tem se mostrado prejudicial na interação entre professores e alunos.

A escola por sua vez, em grande parte dos casos, tem se mostrado um ambiente com características diferentes da realidade do aluno e, o pouco uso de recursos tecnológicos familiares ao jovem é um dos exemplos desse abismo. Dentro deste contexto, estudos acadêmicos mostram que o game pode ser uma alternativa viável ao ser utilizado como recurso pedagógico, pois faz parte do cotidiano dos nativos digitais e possui um potencial significativo para tornar o processo de ensino e aprendizagem mais eficiente.

No entanto, esse discurso acadêmico não tem alcançado a prática social uma vez que exemplos de utilização de games na educação ainda são iniciativas bem tímidas quando comparados ao tamanho da estrutura educacional brasileira.

Embora esse cenário possa representar um grande obstáculo para o desenvolvimento de um processo de ensino e aprendizado mais contextualizado e familiar aos alunos, que são, ou pelo menos deveriam ser os sujeitos de seu próprio conhecimento, isso não pode ser uma barreira para a inserção desse importante recurso em sala de aula.

A análise de propostas como o projeto da professora Marili Bassini, que propôs o ensino de História por meio de jogos digitais como o Assassin's Creed, mostra que é possível atender a demanda dos alunos e, ao mesmo tempo assumir a importante função de docente no mundo contemporâneo, realizando a mediação no processo de ensino e aprendizagem em um 
contexto no qual o aluno é o centro desse processo.

\section{REFERÊNCIAS}

ALVES, Lynn; COUTINHO, Isa de Jesus (orgs.). Jogos Digitais e Aprendizagem: fundamentos para uma prática baseada em evidências. Campinas, SP: Papirus, 2016.

ALVES, Lynn; TELLES, Helyom Viana. Ensino de História e Videogame: problematizando a avaliação de jogos baseados em representações do passado. In: ALVES, Lynn; COUTINHO, Isa de Jesus (orgs.). Jogos Digitais e Aprendizagem: fundamentos para uma prática baseada em evidências. Campinas, SP: Papirus, 2016.

ARRUDA, Eucidio Pimenta. Aprendizagem e Jogos Digitais. Campinas, SP: Editora Alínea, 2011.

BANNEL, Ralph Ings. Educação no século XXI: cognição, tecnologias e aprendizagem. Petrópolis, RJ: Vozes; Rio de Janeiro: Editora PUC. 2016.

BASSINI, Marili. Professora usa Videogame para ensinar História. 28 out. 2015. Disponível em: $<$ http://porvir.org/professora-desenvolveprojeto-usa-games-para-estudar-historia/>. Acesso em 20 jul. 2017.

CARNIELLO, Luciana; RODRIGUES, Bárbara; MORAES, Moema Gomes. A Relação entre os Nativos Digitais, Jogos Eletrônicos e Aprendizagem. In: SIMPÓSIO HIPERTEXTOS E TECNOLOGIAS NA EDUCAÇÃO, REDES SOCIAIS E APRENDIZAGEM, 3., 2010, Recife. Anais... Recife: UFPE, 2010.

GUERRA, Elaine Linhares de Assis. Manual de Pesquisa Qualitativa. Belo Horizonte/MG: Grupo Ănima Educação, 2014. Disponível em: <disciplinas.nucleoead.com.br/pdf/anima_tcc/ge rais/manuais/manual_quali.pdf $>$. Acesso em 30 nov. 2017.

MATTAR, João. Design Educacional: educação a distância na prática. São Paulo: Artesanato Educacional, 2014.

MILITÃO, Rafael; FREITAS, Renan; SALVADOR, Roberta. O uso de Games na Educação a Distância. Revista Cesuca Virtual: Conhecimento sem Fronteiras. v.2, n. 4, Ago/2015. Disponível em:

<http://ojs.cesuca.edu.br/index.php/cesucavirtua I>. Acesso em 16 jul. 2016.

PETRY, Arlete dos Santos. Jogos Digitais e Aprendizagem: algumas evidências de pesquisas. In: ALVES, Lynn; COUTINHO, Isa de Jesus (orgs.). Jogos Digitais e Aprendizagem: fundamentos para uma prática baseada em evidências. Campinas, SP: Papirus, 2016.

RODRIGUES, Alex, et al. Produção de Jogos digitais como recursos didáticos na prática pedagógica. Revista do Seminário Mídias \& Educação do Colégio Pedro II, n. 2, 2016. Disponível em: <http://www.cp2.g12.br/ojs/index.php/midiasee ducacao/article/view/946>. Acesso em 12 nov. 2017.

SILVA, Anderson Arnaldo da. Jogos Eletrônicos com Temáticas Históricas: reflexões sobre saberes e aprendizagens por meio do Assassin's Creed. 2014. 99 f. Monografia (Graduação) Faculdade de História, Universidade Federal de Santa Catarina, Florianópolis, 2014. Disponível em:

<https://repositorio.ufsc.br/xmlui/bitstream/han dle/123456789/131725/TTC\%20\%28Anderson\%2 OArnaldo\%20da\%20Silva\%29\%202014-

2.pdf? sequence $=1 \&$ isAllowed $=y>$. Acesso em 19 abr. 2017.

SIMAN, Lana Mara de Castro. Conversas e controvérsias entre o Nativo e o Migrante: um jogo de espelhos sobre jogos digitais. In: ARRUDA, Eucidio Pimenta. Aprendizagem e Jogos Digitais. Campinas, SP: Editora Alínea, 2011.

VIEIRA, Tiago de Jesus (coord.). A Representação da Revolução Francesa no jogo Assassin's Creed Unity e suas Possibilidades de Aplicação para o Ensino de História. Sorriso: Instituto Federal De Educação, 2016. Disponível em: <http://srs.ifmt.edu.br/media/filer_public/f0/7b/ f07b495d-391c-4b53-bf85-

f26ad7a036d1/tiago_jesus.pdf $>$. Acesso em 24 jul. 2017.

VYGOTSKY, Lev Semyonovich. Pensamento e Linguagem. São Paulo: Martins Fontes, 1987. 
Recebido para publicação em: 25/10/2017

Revisado em: 13/11/2017

Aceito em: 28/01/2018 